\title{
Peranan Kualitas Pelayanan dan Harga Terhadap Kepuasan Konsumen Pengguna E-commerce Shopee Di Politeknik Cendana
}

\author{
Sanny Lonardi ${ }^{1, *}$, Wong Pong Lan ${ }^{2}$, Fauzi Akbar Maulana Hutabarat ${ }^{2}$, Ngajudin Nugroho², Supriyanto \\ ${ }^{1}$ Program Studi Manajemen Perusahaan, Politeknik Cendana, Medan, Indonesia \\ ${ }^{2}$ Program Studi Manajemen Pemasaran, Politeknik Cendana, Medan, Indonesia \\ ${ }^{3}$ Program Studi Administrasi Bisnis, Politeknik LP3I Medan, Medan, Indonesia \\ Email: 2,*sannylonardi@gmail.com \\ Submitted: 15/10/2021; Accepted: 30/10/2021; Published: 30/10/2021
}

\begin{abstract}
Abstrak-Tujuan yang ingin dicapai dalam penelitian ini adalah untuk membuktikan pengaruh kualitas pelayanan dan harga terhadap kepuasan pelanggan e-commerce Shopee di Politeknik Cendana, baik secara parsial maupun simultan. Metode penelitian yang digunakan adalah metode kuantitatif asosiatif melalui kuisioner online. Jumlah responden/sampel sebanyak 35 mahasiswa Politeknik Cendana dari populasi sebanyak 408 orang dengan teknik Accidental Sampling.Hasil penelitian menunjukkan: (1) Kualitas pelayanan memiliki pengaruh terhadap kepuasan pelanggan e-commerce Shopee di Politeknik Cendana, dimana hasil Uji T, nilai Signifikan sebesar 0,005 atau lebih kecil 0,05. (2) harga tidak memiliki pengaruh terhadap kepuasan pelanggan e-commerce Shopee di Politeknik Cendana, dengan hasil Uji T, nilai Signifikan sebesar 0,105 atau lebih besar 0,05. (3) Kualitas pelayanan dan harga memiliki pengaruh terhadap kepuasan pelanggan e-commerce Shopee di Politeknik Cendana dengan hasil Uji F, F ${ }_{\text {hitung }}$ 11,488 dengan signifikansi $\mathrm{F}$ sebesar 0,000 atau nilai signifikansi F lebih kecil dari 0,05.
\end{abstract}

Kata Kunci: Kualitas Pelayanan; Harga; Kepuasan Konsumen

\begin{abstract}
The aim of this research is to prove the effect of service quality and price on Shopee e-commerce customer satisfaction at Cendana Polytechnic, either partially or simultaneously. The research method used is associative quantitative method through online questionnaires. The number of respondents/sample as many as 35 students of the Cendana Polytechnic from a population of 408 people with the Accidental Sampling technique. The results showed: (1) Service quality has an influence on Shopee e-commerce customer satisfaction at Cendana Polytechnic, where the T test results, the significant value is 0.005 or less 0.05 . (2) price has no effect on Shopee e-commerce customer satisfaction at Cendana Polytechnic, with T-test results, a significant value of 0.105 or greater 0.05. (3) Service quality and price have an influence on Shopee e-commerce customer satisfaction at Cendana Polytechnic with F test results, Fcount 11.488 with $\mathrm{F}$ significance of 0.000 or $\mathrm{F}$ significance value less than 0.05 .
\end{abstract}

Keywords: Service Quality; Price; Customer Satisfaction

\section{PENDAHULUAN}

Dalam dunia usaha yang bersifat dinamis, selalu mengalami perubahan setiap saat sehingga pemasaran mempunyai peranan yang sangat penting untuk keberhasilan perusahaan (Hutabarat \& Nugroho, 2020). Pemasaran merupakan salah satu faktor penting guna menjaga kelangsungan hidup perusahaan yang menghadapi persaingan. Dalam menghadapi persaingan itu, pelaku kegiatan bisnis perlu memperhatikan banyak hal (Yuliana, Lisa, Nancy, Chandra, \& Aigan, 2019).Dunia pemasaran telah berkembang sangat pesat di semua sektor usaha, termasukdalam dunia online. Di Indonesia, aktivitas jual beli melalui $e$-commerce sudah menjadi hal yang biasa dilakukan oleh masyarakat. Terdapat pula sarana $e$ commerce yang semakin berkembang di Indonesia, salah satunya adalah Shopee. Berdasarkan survei riset asal Singapura, Blackbox bersama Toluna, bertajuk Into The Light: Understanding What Has Changed for Consumers During COVID19, menyatakan bahwa Situs jual beli Shopee, Tokopedia, serta Grab menjadi situs yang paling banyak dikunjungi dan mendapatkan tingkat kepuasan tertinggi di kalangan pengguna layanan jasa digital di Indonesia.Menurut Analytic Data Advertising (ADA), aktivitas belanja online naik 400\% sejak Maret 2020 akibat pandemi. Bank Indonesia (BI) mencatat, jumah pembelian lewat e-commerce pada bulan Maret 2020 mencapai 98,3 juta transaksi. Angka itu meningkat 18,1\% dibandingkan dengan Februari 2020.

Terdapat beberapa wadah E-commerce yang terkenal di Indonesia, salah satunya adalah Shopee. Shopee merupakan sebuah aplikasi yang bergerak dibidang jual beli secara online dan dapat diakses secara mudah dengan menggunakan smartphone. Shopee pertama kali diluncur sebagai marketplaceconsumer to consumer (C2C). Namun kini mereka telah beralih ke model hibrid C2C dan business to consumer (B2C) semenjak meluncurkan Shopee Mall.

Kepuasan konsumen adalah perasaan seseorang dalam bentuk kepuasan atau kekecewaan dari hasil produk atau jasa yang di bandingkan dengan ekspetasi. Jika kinerja atau hasil memenuhi atau bahkan melebihi harapan, maka pelanggan akan merasa puas. Jika kinerja atau hasil berada dibawah harapan, pelanggan akan merasa tidak puas.

Menurut Tjiptono dalam penelitian(Cucu Sumartini \& Fajriany Ardining Tias, 2019), kepuasan adalah suatu sikap yang diputuskan berdasarkan pengalaman yang didapatkan. Dengan adanya kepuasan konsumen, maka kelangsungan usaha pun akan terjaga. Berikut prinsip kepuasan konsumen, diantaranya: (1) Kepuasan konsumen adalah sesuatu yang penting; (2) Memahami harapan konsumen;(3) Memilih konsumen dengan tepat melalui strategi segmentasi, kemudian bangun kepuasan konsumen;(4) Mempelajari faktor-faktor yang mempengaruhi kepuasan konsumen;(5) Konsumen yang loyal adalah konsumen yang mau complain;(6) Memberi jaminan kepada konsumen;(7) Mendengarkan suara konsumen;(8) Karyawan adalah bagian terpenting dalam memuaskan konsumen;(9) Kepemimpinan adalah teladan dalam kepuasan konsumen. 
Adapun perkembangan ekonomi yang mendukung pemenuhan kepuasan pelanggan yaitu berkembangnya $E$ commerce. E-commerce memiliki peluang yang cukup besar baik dalam menyediakan barang ataupun jasa. E-commerce juga bersifat online sehingga dapat menjangkau konsumen secara luas. E-commerce juga memberikan kemudahan untuk pengguna atau konsumen dalam memesan dan membeli barang serta jasa yang di inginkan. Menurut Kotler \& Amstrong dalam penelitian (Mambu, T. R., Tampi, J. R. E., \& Mukuan, Danny, 2021) E-commerce adalah saluran online yang dapat dijangkau seseorang melalui komputer, yang digunakan oleh pebisnis dalam melakukan aktifitas bisnisnya dan digunakan konsumen untuk mendapatkan informasi dengan menggunakan bantuan komputer yang dalam prosesnya diawali dengan memberi jasa informasi pada konsumen dalam penentuan pilihan.

Shopee hadir dalam bentuk aplikasi yang memudahkan penggunanya dalam melakukan kegiatan berbelanja secara online. Shopee menawarkan berbagai macam produk-produk fashion hingga produk untuk kebutuhan sehari-hari. Shopee juga menghadirkan Live Chat yang memudahkan pembeli agar bisa langsung berbicara dengan si penjual untuk bisa bertransaksi atau bernegosiasi. Memberi kemudahan dalam memilih produk seperti memilih varian motif, warna hingga ukuran dan juga memiliki fitur yang memungkinkan pembeli melakukan penawaran harga. Aplikasi Shopee dapat diunduh dengan gratis melalui App Store dan Google PlayStore. Shopee menjadi E-commerce dengan pengunjung situs bulanan terbesar di Indonesia. Data iPrice menunjukkan, Shopee mendapatkan sebanyak 71,5 juta kunjungan selama kuartal I-2020. Tokopedia dan Bukalapak menempati urutan selanjutnya dengan masing-masing sebanyak 69,8 juta dan 37,6 juta kunjungan.

Jika Shopee mampu memberikan pelayanan yang tepat serta memenuhi apa yang diinginkan konsumen, maka Shopee akan memiliki presepsi yang baik di mata konsumen. Jika konsumen merasa puas dengan apa yang disajikan oleh Shopee, maka konsumen cenderung membandingkan Shopee dengan $e$-commerce lainnya.

Namun, ada beberapa hal yang menghalangi tingkat pembelian konsumen melalui e-commerce. Menurut Kotler dan Keller dalam penelitian (Widyanita, 2018)survei konsumen menunjukkan bahwa hal yang paling signifikan yang menghalangi seseorang untuk berbelanja secara online adalah tidak adanya pengalaman yang menyenangkan, interaksi sosial, dan konsultasi pribadi dengan perwakilan perusahaan. Situasi ketidakpuasan terjadi ketika konsumen telah menggunakan produk atau mengalami jasa yang dibeli dan merasakan bahwa kinerja produk ternyata tidak memenuhi harapan. Ketidakpuasan bisa menimbulkan sikap negatif terhadap merek maupun produsen atau penyediaan jasanya, berkurangnya kemungkinan pembelian ulang, peralihan merek, dan berbagai macam perilaku complain (Tjiptono dalam penelitian(Widyanita, 2018)).

Aplikasi Shopee memang sedang populer pada masa ini. Dapat dilihat dari tabel berikut:

Tabel 1. Presentase Mahasiswa/i Politeknik Cendana Yang Menggunakan Aplikasi Shopee

\begin{tabular}{cccc}
\hline Pertanyaan & Ya & Tidak & Total \\
\hline Pernah menggunakan Shopee & 27 orang (90\%) & 3 orang $(10 \%)$ & 3 orang $(100 \%)$ \\
\hline & Sumber: Penulis (2021)
\end{tabular}

Dari tabel diatas, dapat simpulkan bahwa terdapat 90 persen mahasiswa Politeknik Cendana pernah menggunakan aplikasi Shopee. Dari 90 persen tersebut terdapat beberapa mahasiswa yang menyatakan ketidakpuasan dalam menggunakan aplikasi Shopee yang dapat dilihat dari tabel berikut.

Tabel 2. Presentase Kepuasan Mahasiswa/i Politeknik Cendana Dalam Menggunakan Aplikasi Shopee

\begin{tabular}{cccc}
\hline Pertanyaan & Ya & Tidak & Total \\
\hline Perasaan puas menggunakan Shopee & 22 orang (95\%) & 5 orang (5\%) & 27 orang (100\%) \\
\hline
\end{tabular}

Sumber: Penulis (2021)

Berdasarkan tabel diatas, maka dapat disimpulkan bahwa masih banyak mahasiswa yang merasa tidak puas dalam menggunakan aplikasi Shopee. Ketidakpuasan konsumen biasanya dikarenakan oleh beberapa faktor. Menurut Tjiptono dalam (Cucu Sumartini \& Fajriany Ardining Tias, 2019) terdapat lima faktor yang dapat mempengaruhi kepuasan seorang konsumen yaitu kualitas produk, harga, kualitas pelayanan, faktor emosional, biaya dan kemudahan untuk mendapatkan produk.

Tujuan dari penelitian ini adalah (1) untuk membuktikan secara empiris pengaruh kualitas pelayanan terhadap kepuasan konsumen e-commerce Shopee Di Politeknik Cendana;(2) untuk membuktikan secara empiris pengaruh harga terhadap kepuasan konsumen e-commerce Shopee Di Politeknik Cendana;(3) untuk membuktikan secara empirits pengaruh kualitas pelayanan dan harga terhadap kepuasan konsumen e-commerce Shopee Di Politeknik Cendana

\section{KERANGKA TEORI}

\subsection{Kualitas Pelayanan}

Menurut Tjiptono dalam penelitian, kualitas layanan didefinisikan sebagai tingkat keunggulan yang diharapkann dan pengendalian atas tingkat keunggulan tersebut untuk memenuhi keinginan konsumen. Kualitas pelayanan dapat memberikan dorongan yang kuat, pada konsumen untuk membentuk suatu hubungan yang baik dengan badan usaha (Kotler \& Keller, 2016). Konsumen menilai suatu kualitas layanan tidak hanya berdasarkan pada hasil dari suatu layanan 
tetapi juga harus memperhitungkan proses pemberian layanan tersebut. Kualitas pelayanan dapat diukur dari hal-hal sebagai berikut (Tjiptono, 2018)):

a. Keandalan (reliability), yaitu kemampuan untuk memberikan pelayanan yang sesuai dengan janji yang ditawarkan.

b. Daya tanggap (responsiveness), yaitu respon atau kesigapan karyawan dalam membaru pelanggan dan memberikan pelayanan yang cepat dan tanggap.

c. Jaminan (assurance), yaitu meliputi kemampuan karyawan atas pengetahuan terhadap produk secara tepat, kualitas keramah tamahan, perhatian dan kesopanan dalam memberikan pelayanan.

d. Empati (emphaty), yaitu perhatian secara individual yang diberikan perusahaan kepada pelanggan seperti kemudahan untuk menghubungi perusahaan, kemampuan karyawan untuk berkomunikasi dengan pelanggan dan usaha perusahaan untuk memhami keinginan dan kebutuhan pelanggannya.

e. Bukti nyata (tangibles), meliputi fasilitas fisik seperti ruangan, sarana komunikasi dan penampilan karyawan.

\subsection{Harga}

Harga merupakan salah satu variabel dari Bauran pemasaran yang merupakan penetapan harga jual barang yang sesuai dengan kualitas barang dan dapat dijangkau oleh konsumen(Ivone, Wongnur, Arwin, Lisa, \& Ciamas, 2019). Tjiptono dalam (Nuryati \& Aini, 2019), menyebutkan penetapan harga merupakan pemilihan yang dilakukan perusahaan terhadap tingkat harga umum yang berlaku untuk produk tertentu, relatif terhadap harga para pesaing. Menurut Kotler dan Amstrong dalampenelitian(AMILIA, 2017), terdapat empat indikator yang mencirikan harga, yaitu:

1. Keterjangkauan harga, harga yang terjangkau adalah harapan konsumen sebelum mereka melakukan pembelian. Mereka akan mencari produk yang harganya dapat mereka jangkau.

2. Kesesuaian harga dengan kualitas produk. Untuk produk tertentu, biasanya konsumen tidak merasa keberatan apabila harus membeli dengan harga relatif mahal asalkan kualitas produknya baik. Namun, konsumen lebih mengharapkan produk dengan harga lebih murah dan kualitas yang baik.

3. Daya saing harga, perusahaan menetapkan harga jual suatu produk dengan mempertimbangkan produk yang dijual oleh pesaingnya agar produk dapat bersaing di pasar.

4. Kesesuaian harga dengan manfaat, konsumen terkadang mengabaikan harga suatu produk namun lebih mementingkan manfaat dari produk.

\subsection{Kepuasan konsumen}

Kepuasan konsumen adalah perasaan seseorang dalam bentuk kepuasan atau kekecewaan dari hasil produk atau jasa yang di bandingkan dengan ekspetasi. Menurut Tjiptono dalam penelitian(Cucu Sumartini \& Fajriany Ardining Tias, 2019) terdapat lima faktor yang dapat mempengaruhi kepuasan seorang konsumen yaitu:

1. Kualitas produk, pelanggan akan merasa puas bila hasil evaluasi mereka menunjukkan bahwa produk yang mereka gunakan berkualitas.

2. Harga, produk dengan kualitas yang sama tetapi menetapkan harga yang relatif murah akan memberi nilai yang tinggi kepada pelanggannya.

3. Kualitas pelayanan, pelanggan akan merasa puas jika mereka mendapatkan pelayanan yang baik atau sesuai dengan harapannya.

4. Faktor emosional, pelanggan akan merasa bangga dan mendapatkan keyakinan bahwa orang lain kagum kepadanya bila menggunakan produk merek tertentu.

5. Biaya dan kemudahan untuk mendapatkan produk atau jasa, pelanggan yang tidak perlu mengeluarkan biaya tambahan atau membuang waktu untuk mendapatkan suatu produk, cenderung puas terhadap produk.

\section{METODOLOGI PENELITIAN}

Metode analisis yang digunakan adalah analisis asosiatif yaitu metode penelitian yang bertujuan untuk mengetahui hubungan kausalitas antara variabel melalui suatu pengujian melalui suatu perhitungan statistik didapat hasil pembuktian yang menunjukkan hipotesis ditolak atau diterima(Sugiyono, 2016). Analisis kuantitatif dilakukan setelah peneliti mendapatkan data penelitian hasil pengukuran variabel yang dioperasionalkan dengan menggunakan instrumen

Tempat yang dipilih untuk dilakukan penelitian ini adalah di Politeknik Cendana dan pelaksanaan penelitian ini dilakukan dalam kurun enam bulan yakni dari bulan Desember 2020 sampai dengan Mei 2021. Dalam penelitian ini ada dua variabel yang digunakan yaitu variabel independen adalah variabel yang mempengaruhi atau yang menjadi sebab perubahannya atau timbulnya variabel dependen (Sugiyono, 2016). Dalam penelitian ini yang termasuk variabel independen adalah Kualitas Pelayanan $\left(\mathrm{X}_{1}\right)$ dan Harga $\left(\mathrm{X}_{2}\right)$. Yang kedua adalah variabel dependen yaitu variabel yang dipengaruhi atau yang menjadi akibat karena adanya variabel bebas. Variabel dependen dalam penelitian ini adalah kepuasan konsumen (Sugiyono, 2016).

Populasi dalam penelitian ini adalah mahasiswa-mahasiswi Politeknik Cendana sebanyak 408 orang. Jumlah sampel yang diperoleh sebanyak 35 orang dengan kriteria dan karakteristik pernah menggunakan Shopee (minimal 1 kali transaksi) dan bersedia memberikan informasi dalam jangka waktu dari tanggal 18 Mei sampai 21 Mei. Penelitian ini menggunakan teknik Accidental Sampling adalah siapa saja secara kebetulan bertemu dengan peneliti dapat digunakan sebagai sampel, bila dipandang orang yang kebetulan ditemui itu cocok dengan sumber data(Sugiyono, 2016). 


\subsection{Koefisien Determinasi}

Uji determinasi bertujuan untuk mengetahui sejauh mana variabel X (kualitas pelayanan dan harga) dapat mempengaruhi variabel Y (kepuasan pelanggan). Adapun cara menghitung koefisien determinasi yaitu:

$K d=R^{2} \times 100 \%$

Dimana:

$\mathrm{Kd}=$ Koefisien Determinasi

$\mathrm{R}^{2}=$ Koefisiense Korelasi

\subsection{Regreasi Linear Berganda}

Analisis regresi linear berganda digunakan untuk mengetahui arah dan seberapa besar pengaruh variabel independen terhadap variabel dependen. Berikut rumus yang digunakan untuk menghitung regreasi linear berganda:

Dimana:

$$
Y=\alpha+\beta_{1} X_{1}+\beta_{2} X_{2}+\varepsilon
$$

$\beta_{n}=$ Koefisien Regresi

$X_{1}=$ Kualitas pelayanan

$X_{2}=$ Harga

\subsection{Uji Kelayakkan Model (Uji F)}

Pada dasarnya uji statistik F menunjukkan apakah semua variabel independen yang dimasukkan dalam model mempunyai pengaruh secara simultan terhadap variabel dependen. Uji $F$ dilakukan dengan membandingkan nilai $F_{\text {hitung }}$ dengan $F_{\text {tabel }}$ dan melihat nilai signifikansi 0,05 dengan cara sebagai berikut:

1. Bila $F_{\text {hitung }}>F_{\text {tabel }}$ atau probabilitas $<$ nilai signifikan $(\operatorname{Sig}<0,05)$, maka model penelitian dapat digunakan.

2. Bila $F_{\text {hitung }}<F_{\text {tabel }}$ atau probabilitas $>$ nilai signifikan $(\mathrm{Sig}>0,05)$, maka model penelitian tidak dapat digunakan.

\subsection{Uji Parsial (Uji T)}

Uji T pada dasarnya menunjukkan seberapa jauh pengaruh satu variabel independen secara individual dalam menerangkan variasi variabel dependen. Pengujian dilakukan dengan menggunakan signifikansi level 0,05 ( $\alpha=5 \%)$. Penerimaan atau penolakan hipotesis dilakukan dengan kriteria:

1. Jika nilai signifikan $>0,05$ maka hipotesis ditolak (koefisien regresi tidak signifikan). Ini berarti variabel independen tidak mempunyai pengaruh secara signifikan terhadap variabel dependen.

2. Jika nilai signifikan $<0,05$ maka hipotesis diterima (koefisien regresi signifikan). Ini berarti variabel independen mempunyai pengaruh secara signifikan terhadap variabel dependen

\subsection{Hipotesis}

Dari penjelasan di atas, maka dihasilkan kerangka pikir seperti berikut:

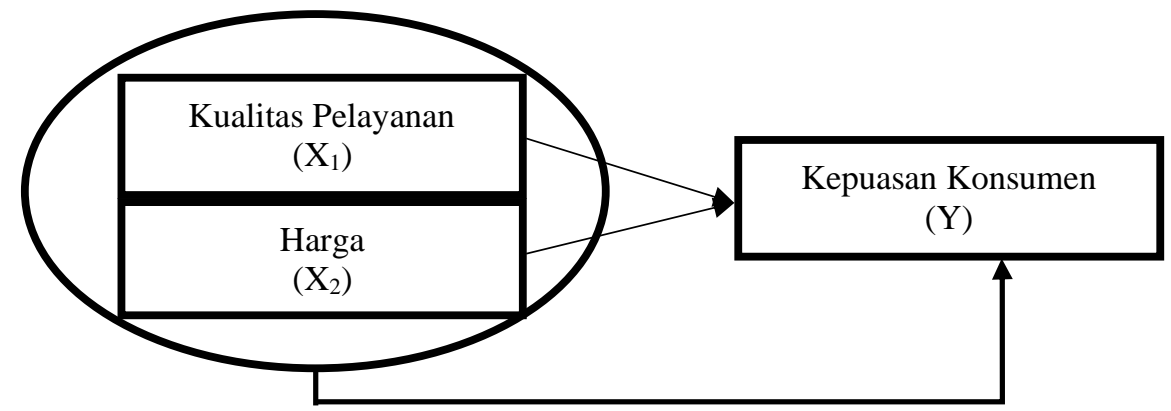

Gambar 1. Kerangka Pikiran

Berikut hipotesis yang terbentuk dari simpulan di atas

Pengaruh Kualitas Pelayanan terhadap kepuasan konsumen

Hipotesis 1:

Ho: Tidak ada pengaruh yang berarti kualitas pelayanan terhadap kepuasan konsumen pengguna Shopee di Politeknik Cendana.

Ha: Ada pengaruh yang berarti kualitas pelayanan terhadap kepuasan konsumen pengguna Shopee di Politeknik Cendana Pengaruh Harga terhadap kepuasan konsumen

Hipotesis 2:

Ho: Tidak ada pengaruh yang berarti harga terhadap kepuasan konsumen pengguna Shopee di Politeknik Cendana.

Ha: Ada pengaruh yang berarti harga terhadap kepuasan konsumen pengguna Shopee di Politeknik Cendana.

Pengaruh Kualitas Pelayanan danHarga terhadap Kepuasan pelanggan.

Hipotesis 4: 
Ho: Tidak ada pengaruh yang berarti kualitas pelayanan dan harga terhadap kepuasan konsumen pengguna Shopee di Politeknik Cendana.

Ha: Ada pengaruh yang berarti kualitas pelayanan dan harga terhadap kepuasan konsumen pengguna Shopee di Politeknik Cendana.

\section{HASIL DAN PEMBAHASAN}

Kontribusi yang diberikan oleh variabel bebas terhadap variabel terikat dapat dilihat darii perhitungan koefisien determinasi. Jika nilai koefisien determinasi mendekati angka 0 berarti kemampuan variabel bebas dalam mempengaruhi variabel terikat sangat kecil. Sebaliknya, jika nilai koefisien determinasi mendekati angkat 1 berarti kemampuan variabel bebas dalam mempengaruhi variabel terikat sangat besar. Hasil dari perhitungan koefisien determinasi pada tabel berikut:

Tabel 3. Ringkasan Hasil Uji Koefisien Determinasi

\begin{tabular}{lc}
\hline Variabel & Nilai Koefisien Determinasi $\left(\mathrm{R}^{2}\right)$ \\
\hline $\mathrm{X}_{1}-\mathrm{Y}$ & 0,414 \\
$\mathrm{X}_{2}-\mathrm{Y}$ & 0,340 \\
$\mathrm{X}_{1}, \mathrm{X}_{2} \mathrm{Y}$ & 0,486 \\
\hline \multicolumn{2}{|c}{ Sumber: Sumber data primer diolah oleh penulis (2021) }
\end{tabular}

Pada tabel di atas, dapat dilihat bahwa nilai koefisien determinasi $\left(\mathrm{R}^{2}\right)$ antara kualitas pelayanan $\left(\mathrm{X}_{1}\right)$ terhadap kepuasan konsumen (Y) adalan 0,414 atau 41,4\%, maka dapat disimpulkan bahwa kualitas pelayanan berpengaruh terhadap kepuasan konsumen sebesar 41,4\% sedangkan sisanya 58,6\% dipengaruhi oleh faktor lainnya. Nilai koefisien determinasi $\left(\mathrm{R}^{2}\right)$ antara harga $\left(\mathrm{X}_{2}\right)$ terhadap kepuasan konsumen $(\mathrm{Y})$ sebesar 0,340 atau 34\%, maka dapat disimpulkan bahwa harga berpengaruh terhadap kepuasan konsumen sebesar 34\% sedangkan sisanya $66 \%$ dipengaruhi oleh faktor lainnya. Nilai koefisien determinasi $\left(\mathrm{R}^{2}\right)$ antara kualitas pelayanan $\left(\mathrm{X}_{1}\right)$ dan harga $\left(\mathrm{X}_{2}\right)$ terhadap kepuasan konsumen $(\mathrm{Y})$ sebesar 0,486 atau 48,6\%, maka dapat disimpulkan bahwa kualitas pelayanan dan harga terhadap kepuasan konsumen sebesar 48,6\% sedangkan 51,4\% dipengaruhi oleh faktor lainnya.

\subsection{Hasil Regresi Berganda}

Hasil dari perhitungan regresi berganda pada tabel berikut:

Tabel 4. Ringkasan Hasil Regresi Berganda

\begin{tabular}{ll}
\hline \multicolumn{1}{c}{ Variabel } & Koefisien Regresi $(\boldsymbol{\beta})$ \\
\hline Kualitas Pelayanan & 0,846 \\
Harga & 0,433 \\
Kualitas Pelayanan dan Harga & 1,481 \\
\hline Sumber: Sumber data primer diolah oleh penulis (2021)
\end{tabular}

Persamaan regresi berganda yang terbentuk dari data diatas adalah sebagai berikut:

$$
Y=1,481+0,846 x_{1}+0,433 x_{2}
$$

Persamaan regresi di atas mempunyai arti bahwa koefisien regresi variabel kualitas pelayanan sebesar 0,846 menyatakan bahwa jika kualitas produk mengalami kenaikan satu satuan, maka kepuasan konsumen akan mengalami kenaikan sebesar 0,846. Koefisien regresi variabel harga sebesar 0,433 menyatakan bahwa jika harga mengalami kenaikan satu satuan, maka kepuasan konsumen akan mengalami kenaikan sebesar 0,433.

\subsection{Hasil Uji F}

Uji Simultan atau Uji F digunakan untuk mengetahui apakah variabel bebas yaitu kualitas pelayanan dan hargasimultan berpengaruh terhadap kepuasan konsumen. Berdasarkan hasil perhitungan secara simultan pengaruh kualitas pelayanan dan harga terhadap kepuasan konsumen, pada taraf signifikansi 0,05 atau 5\% diperoleh $F_{\text {hitung }} 15,122$ dengan signifikansi $F$ sebesar 0,000. Nilai signifikansi $F$ yang dihasilkan kurang dari 0,05 dengan $F_{\text {tabel }}$ sebesar 3,29 maka dapat disimpulkan bahwa secara simultan kualitas pelayanan dan harga memiliki pengaruh yang signifikan terhadap kepuasan konsumen $e$ commerce Shopee di Politeknik Cendana.

Tabel 5. Ringkasan Hasil Uji F

\begin{tabular}{cccl}
\hline Variabel & Sig & F hitung & \multicolumn{1}{c}{ Kesimpulan } \\
\hline $\mathrm{X}_{1}, \mathrm{X}_{2}-\mathrm{Y}$ & 0,000 & 15,122 & $\begin{array}{l}\text { Kualitas pelayanandan harga memiliki pengaruh } \\
\text { yang signifikan terhadap kepuasan konsumen } e- \\
\end{array}$ \\
& & \begin{tabular}{l} 
commerce Shopee. \\
\hline
\end{tabular}
\end{tabular}




\subsection{Hasil Uji T}

Uji parsial atau Uji T digunakan untuk menunjukkan pengaruh secara individu variabel bebas yang ada dalam model terhadap variabel terikat. Hal ini dimaksudkan untuk mengetahui seberapa jauh pengaruh masing-masing variabel bebas terhadap variabel terikat. Apabila nilai signifikansi kurang dari 0,05 maka dapat disimpulkan secara parsial berpengaruh signifikan terhadap variabel terikat.

Tabel 6. Ringkasan Hasil Uji T

\begin{tabular}{lcl}
\hline Variabel & Sig & Kesimpulan \\
\hline X1-Y & 0,005 & Ha1 diterima \\
X2-Y & 0,105 & Ha2 ditolak \\
\hline
\end{tabular}

Berdasarkan hasil perhitungan, secara parsial pengaruh kualitas pelayanan terhadap kepuasan konsumen diperoleh nilai Sig sebesar 0,005 atau kecil dari 0,05 yang berarti hipotesis mengenai adanya pengaruh kualitas pelayanan terhadap kepuasan konsumen diterima. Secara parsial pengaruh harga terhadap kepuasan konsumen diperoleh nilai Sig sebesar 0,105 atau lebih dari 0,05 yang berarti hipotesis mengenai adanya pengaruh harga terhadap kepuasan konsumen ditolak.

\subsection{Pembahasan}

Dari hasil uji hipotesis maka diperoleh: variabel kualitas pelayanan terhadap kepuasan konsumen menghasilkan nilai signifikansi dari hasil Uji T (Parsial) yaitu 0,005 atau lebih kecil dari 0,05. Maka dari itu, terdapat pengaruh kualitas pelayanan terhadap kepuasan konsumen. Variabel harga terhadap kepuasan konsumen menghasilkan nilai signifikansi dari hasil Uji T (Parsial) lebih besar dari 0,05. Maka dari itu, tidak terdapat pengaruh harga terhadap kepuasan konsumen. Sedangkan, Secara simultan atau hasil Uji F, kualitas pelayanan dan harga terhadap kepuasan konsumen menghasilkan nilai signifikansi yang lebih kecil dari 0,05. Maka dari itu, terdapat pengaruh kualitas pelayanan dan harga terhadap kepuasan konsumen.

\section{KESIMPULAN}

Secara empiris kualitas pelayanan memiliki pengaruh terhadap kepuasan konsumen e-commerce Shopee di Politeknik Cendana. Hal ini diperkuat nilai koefisien determinasi (R2) antara kualitas pelayanan $\left(\mathrm{X}_{2}\right)$ terhadap kepuasan konsumen (Y) adalan 0,414 atau 41,4\%, maka dapat disimpulkan bahwa kualitas pelayanan berpengaruh terhadap kepuasan konsumen sebesar 41,4\% sedangkan sisanya 58,6\% dipengaruhi oleh faktor lainnya. Berdasarkan hasil Uji T, kualitas pelayanan terhadap kepuasan konsumen memperoleh nilai Signifikan sebesar 0,005 atau lebih kecil 0,05 Ha hipotesis 1 diterima. Secara empiris harga tidak memiliki pengaruh terhadap kepuasan konsumen e-commerce Shopee di Politeknik Cendana. Hal ini sesuai dengan hasil Uji T, dimana nilai Signifikan sebesar 0,105 atau lebih besar 0,05, maka Ha hipotesis 2 ditolak. Secara empiris kualitas pelayanan dan harga memiliki pengaruh terhadap kepuasan konsumen $e$-commerce Shopee di Politeknik Cendana. Hal ini diperkuat dengan hasil Uji F, F atau nilai signifikansi $\mathrm{F}$ lebih kecil dari 0,05, maka Ha hipotesis 3 diterima.

\section{DAFTAR PUSTAKA}

AMILIA, S. (2017). Pengaruh Citra Merek, Harga, dan Kualitas Produk terhadap Keputusan Pembelian Handphone Merek Xiaomi di Kota Langsa. Jurnal Manajemen Dan Keuangan Unsam, 6(1), 660-669.

Cucu Sumartini, L., \& Fajriany Ardining Tias, D. (2019). Analisis Kepuasan Konsumen Untuk Meningkatkan Volume Penjualan Kedai Kopi Kala Senja. Jurnal E-Bis (Ekonomi-Bisnis), 3(2), 111-118. https://doi.org/10.37339/e-bis.v3i2.124

Hutabarat, F. A. M., \& Nugroho, N. (2020). Analisis Promosi Penjualan Sepeda Motor di Medan (Studi Kasus pada PT Daya Anugerah Motor). 1(September), 35-40.

Ivone, I., Wongnur, T., Arwin, A., Lisa, L., \& Ciamas, S. E. (2019). Pengaruh Biaya Promosi Terhadap Peningkatan Jumlah Murid di Sempoa Sip Sumut Dan Aceh. Jurnal Ilmiah Simantek, 3(2).

Kotler, P., \& Keller, K. L. (2016). Marketing Management. London: Pearson Education, Inc.

Mambu, T. R., Tampi, J. R. E., \& Mukuan, Danny, D. S. (2021). Kepercayaan Konsumen, Kualitas Layanan Terhad ap Keputusan Pembelian Pada Aplikasi E-Commerce Shopee Di Kota Tondano. Productivity, 2(1), 79-84.

Nuryati, N., \& Aini, A. N. (2019). INCREASE IN PURCHASING SWCISIONS FOR NEXIAN PHONE THROUGH PRICE, PRODUCT QUALITY AND EASE OF USE ONLINE AT THE LAZADA SITE (Case Study Of STIE AUB Surakarta Students). 6(1), 44-53.

Sugiyono. (2016). Metode Penelitian Kuantitatif, Kualitatif dan R\&D. Bandung: PT Alfabet.

Tjiptono, F. (2018). Strategi pemasaran (Promosi, Iklan, Media Sosial, Kompetitif, Market, Distribusi, Pelanggan, Pasar, Branding, Produk, Harga).

Widyanita, F. A. (2018). ANALISIS PENGARUH KUALIATAS PELAYANAN E-COMMERCE TERHADAP KEPUASAN KONSUMEN SHOPEE INDONESIA PADA MAHASISWA FAKULTAS EKONOMI UII PENGGUNA SHOPEE. Journal of Materials Processing Technology, 1(1), 1-8.

Yuliana, Y., Lisa, L., Nancy, N., Chandra, W., \& Aigan, W. (2019). Analisis Penerapan Promosi Pada PT. Adam Dani Lestari Medan. Seminar Nasional Teknologi Komputer \& Sains (SAINTEKS), 106-108. 